\title{
sciendo
}

\section{Public sector innovation performance in Federation of Bosnia and Herzegovina: An exploratory factor analysis}

\author{
Lamija Krndzija \\ Federal Institute for Development Programming, Bosnia and Herzegovina \\ lamija.krndzija@fzzpr.gov.ba
}

\begin{abstract}
Innovation has nowadays become the main force to cope with challenging times in the fast-changing world. The influence of public sector innovation (PSI) in resolving dynamic economical and societal challenges is undisputable. Regardless of the numerous advantages of innovation in the public sector (PS) which have been recognised worldwide, the concept of public sector innovation is still novel for the Federation of Bosnia and Herzegovina $(\mathrm{FBiH})$. Moreover, there is limited empirical evidence which would facilitate the understanding of public sector innovation performance. The purpose of this paper is to identify main components of PSI performance. The primary research data was obtained through a survey with closeended questions which was completed by the public sector institution employees in $\mathrm{FBiH}$. The exploratory factor analysis (EFA) was used in order to determine the principal components of measuring public sector innovation performance. The EFA returned the factor-structures for all four suggested constructs, innovation capabilities, wider sector conditions for innovation, sources of information and the share of creative occupation, explaining between $65 \%$ and $78 \%$ of the variance of the innovation performance measurement construct. The results from the exploratory factor analysis provided a distinct estimation on the factor structure of measuring PSI. The paper has provided and analysed the first instrument in measuring public sector innovation performance in $\mathrm{FBiH}$.
\end{abstract}

Keywords: exploratory factor analysis, government, innovation performance, public sector.

JEL classification: $\mathrm{H} 11, \mathrm{O} 31, \mathrm{O} 32$.

DOI: $10.2478 /$ crebss-2021-0002

Received: August 12, 2020

Accepted: December 14, 2020

\section{Introduction}

Innovation in the public sector, according to Tiganasu, Pascariu, Nijkamp (2019), consists of various processes or innovation environments. The innovation capability of an institution depends basically on the institutional quality. According to Head (2013), improvement of leadership should be an immediate objective for every institution. Even though innovation itself has many definitions, public sector innovation is certainly 
connected to leadership and the application of a synergetic approach (Lewis, Ricard, Klijn, 2018). Innovation may not only be related to governmental effectiveness, but also to institutional and societal innovative behaviour, that in turn creates an innovation-oriented environment, or as Tiganasu, Pascariu, Nijkamp (2019) say, an innovation architecture.

Public sector institutions function in a bureaucracy framework which is limited by the budget constraints, and are, according to Bommert (2010) under constant pressure to resolve many challenges of the country. In this regard, public sector institutions have to be innovative and optimally use the resources in order to successfully fulfil the citizen's expectations. Furthermore, it is necessary to enhance the innovation capabilities of the public sector (PS), including its activities and performance. This is why it is crucial to embellish the understanding of public sector innovation (PSI) ecosystem.

There is currently a growing interest in measuring innovation performance of the public sector, which can mainly be associated with several initiatives within the European Union and Australia, as Audenaert et al. (2019) explain. When it comes to measuring innovation performance in the private sector, studies as Gittelman (2006), Kafouros et al. (2008), Lundvall, Nielsen (2007), Lin et al. (2011), have analysed and provided better understanding and knowledge in this regard. Nevertheless, as Bloch, Bugge (2013) underline, there is a lack of adequate and advanced studies in measuring PSI performance which additionally limits the knowledge on public sector innovation. Therefore, it is crucial to develop appropriate instruments for measuring PSI and to target the present knowledge gaps in this area.

The main contribution and aim of this paper is to develop a measuring instrument of PSI performance in the context of Federation of Bosnia and Herzegovina. According to Tiganasu, Pascariu, Nijkamp (2019) and Ramli, Abu-Hassan, Arifin (2017) the approach of evaluating public sector performance through perceptions is a broadly established approach, that is practiced by many international organisations and experts due to its high importance. Even though this approach exists in other countries, this is the first instrument of this kind developed in $\mathrm{FBiH}$. In that regard, this primary research will provide an empirical support on the reliability and the identification of several factors of each construct and deepen the understanding on measuring public sector innovation performance in the current literature.

The main research method is exploratory factor analysis. The instrument will be based on four latent constructs, namely, innovation capabilities, wider sector conditions for innovation, sources of information and the share of creative occupation.

The first section of the paper outlines in detail the main characteristics of public sector innovation, the role which innovation has in enhancing public sector performance, and reviews several past studies which were analysing PSI performance. The following section describes the data and methods in the research. Finally, research results are presented and elaborated, with an emphasis on the main latent constructs of PSI performance. The paper ends with a summary of the main research findings and recommendations for further research.

\section{Literature review}

When it comes to business performance, Armbruster et al. (2008) explain that institutional innovativeness is focal in terms of competitiveness. The institutional innovation facilitates and contributes to an efficient implementation of product and process innovation. Moreover, innovation directly impacts the competitive advantage of, especially in regards to productivity, quality, and flexibility which is 
enhanced in an institution. Damanpour, Schneider (2006) claim that innovation is usually regarded as a prerequisite of efficiency of any institution, and sometimes even the only mean to survive. Especially nowadays, under the challenging circumstances of increasing international competition, new demands for quality, and the ever fastdeveloping technology, innovation is a crucial mean in achieving competitive advantage and economic growth. Also, Damanpour, Schneider (2008) emphasise that innovation is the origin of development and growth of an institution.

According to Tiganasu, Pascariu, Nijkamp (2019) it is challenging to assess the real meaning of innovation in the public sector, as it is still not clear what public sector innovation encompasses in comparison to the private sector. Innovation is depending on the context, related to institutional architecture, products or processes. Consequently, the factors which impact the innovation culture and the creation of an innovation-oriented environment in the public sector have to be determined (Tiganasu, Pascariu, Nijkamp, 2019).

Mulgan, Albury (2003) define innovation as an essential activity of any public sector, through which it is possible to satisfy all citizen expectations and needs. Innovation in the PS is described as the creation of novel ideas, implementation of new approaches which aim to enhance the quality of public services, or simply creating value and providing a better answer to societal needs. Furthermore, innovation enhances the performance and efficiency of public services and decreases the costs.

Bailey (2002) claims that the government institutions and its activities comprise the public sector. In most cases, the public sector is associated to bureaucratic silos, accompanied by delays and inertia. Due to these slow dynamics, there is a great pressure on the public sector to embrace innovation in all processes. Sørensen, Torfing (2011) explain that the PS requires innovation more than ever before as it is steadily shifting to the provision of intangible public services.

The public sector has always, as Vigoda-Gadot et al. (2008) notice, coped to accomplish its ideals. Albury (2005) emphasises the increasing pressure which the public sector is experiencing, in the form of demands for greater efficiency, better performance, or more personalised services. These new circumstances require that the public sector offers services which are more appropriated to the society in general, but also not generic and more tailored to the individual. Furthermore, Ricard et al. (2017) underline that the institutions are pressured to convey more value on one unit of public money and to explore some novel approach in coping with the financial crisis or demographic changes.

Governments have recently realised that with innovation they can respond better to the many environmental and social challenges. Schot, Steinmueller (2018) explain that the long-existing issues as poverty, climate change, or pollution, are nowadays challenges and opportunities for governmental innovation. According to Schot, Steinmueller (2018), innovation enables the institutions in public sector to enhance the quality of life of their citizens and contributes to stronger communities through. Keping (2018) also claims with certainty that the prospective of any efficient public sector will rely on innovation.

Bartlett, Dibben (2002) mention the increasing fiscal pressure as one additional factor which forces the public sector to innovate and maximise the efficiency of public service provision which would enable them to do less, but still achieve better results. According to Audenaert et al. (2019) the importance of innovation in the public sector is also seen in the performance effect. Through innovation, public sector institutions can improve the quality of life for their citizens and make the communities stronger. 
Factors that can influence the innovation performance in the PS, as Taylor (2018) describes, encompass superior leadership and project management skills, networking and partnerships, and importantly the political and social engagement. Kurz, Hüsig, Dowling (2018) argue that innovation usually comes from higher-level employees in the public sector. According to Mongey (2013), the management is the one who supports innovation, improves people management, and the establishes a common entrepreneurial objective within the institution. The willingness and eagerness of the whole management is focal for the favourable implementation of innovation activities in the institution.

It is also indicated that an innovative idea can occur at any institutional level and from any employee. Hence, PSI should intend offer new opportunities for their employees and encourage their innovative behaviour. Even though motivation is for the most part intrinsic, it may not be neglected that it is highly dependent on the overall working environment which has to be open to innovation (Organization for Economic Cooperation and Development, 2017).

Mongey (2013) proposes rewards as one of the ways to effectively stimulate innovation. Hence, the management has a duty to offer the employees motivational rewards. PS institutions should inspire, encourage and appreciate their employees in innovating. Inspiration is, in most cases, intrinsic, but it is also highly dependent on the working environment, whereas opportunity refers mostly on the provision of trust and independence, and resources. Rivera-León, Simmonds, Roman (2012) explain that it is probable that innovation will occur in institutional cultures, which stimulate and provide rewards based on competencies and personal endeavour. Unfortunately, there are still many public sector institutions in which deficient improvement attempts are punished, so that many new ideas are prevented in the beginning due to a fear of failure.

Daglio, Gerson, Kitchen (2014) underline that searching and sharing information is essential for the improvement of innovation. Furthermore, Abukhait, Bani-Melhem, Zeffane (2019) explain that knowledge sharing includes a mutual exchange of task information and working expertise in which it enhances innovative employee behaviour and fosters critical thinking.

Mongey (2013) claims that every successful institution requires an overall understanding of the internal conditions affecting innovation. Bland et al. (2010) also emphasise that resources, talent and quality skills are necessary in order to place innovative ideas into practice. The support of the whole institutional structure is a key for a successful implementation of the innovative institutional activities. Furthermore, Andersen, Jakobsen (2018) claim that in order to understand the public sector performance, it is also important to consider the external factors, as the political pressure, horizontal factors as compliance pressures, citizen needs and others.

Tiganasu, Pascariu, Nijkamp (2019) claim that the simplest way of assessing the public sector performance is through the governmental capabilities to accomplish its objectives in a timely and efficient manner. Nevertheless, assessing the governmental performance in terms of innovation is very difficult, as there is a lack of basic theory. Some researchers evaluate performance through the indicators of output and outcome in some general areas of public sector policy, as for example in health, education, security or social welfare. Still, there is an issue in regards to an accurate quantification, especially in countries which have a weak institutional setting, and also a systematic assessment on the performance cannot be performed, as for many areas there is no genuine comparative data on all countries. Other researchers use secondary data or the survey-based approach in order to assess the performance by 
combining the results obtained through surveys of citizens or companies (Tiganasu, Pascariu, Nijkamp, 2019).

The lack of innovation was a focal issue of many management researches during the 1990's that focused on the implementation of New Public Management (NPM). According to Vigoda-Gadot at al. (2008), one of the main PS changes of the NPM comprised the inclusion of market-based mechanisms, as for example, performance measurement tools. From this period and on, the interest about PSI has increased gradually, but most researches were still using case studies. As Hollanders, Arundel, Buligescu (2013) claim, the survey-based approach in examining public sector innovation is a rather new undertaking.

As time went by, according to Hollanders, Arundel, Buligescu (2013), the attention has moved to the application of innovation surveys. Some of the recently most important surveys on public sector innovation are the National Public Sector Innovation Index (NESTA) and Measuring Public Innovation in the Nordic countries (MEPIN) project. Hughes, Moore, Kataria (2011) explain that the NESTA surveyed the local government institutions in England. The MEPIN was implemented in the Nordic countries as a survey involving over 2000 regional and local government institutions. The methodology on measuring PSI was equally tackled by both surveys. NESTA analysed the present practices in England and overseas in regards to measuring PSI. Moreover, the paper resulted in three possible paths in developing a PSI index, a government research and development scoreboard, an innovation scoreboard and a multi-factor productivity index.

Various notable initiatives have happened in Europe and outside with the aim to enhance the understanding of public sector innovation and to examine the data collection tools, whether that has been the MEPIN, or the NESTA project from 2010. Nevertheless, Hollanders, Arundel, Buligescu (2013) emphasise that Europe requires more and enhanced data on PSI.

Two distinctive Innobarometer surveys were launched during the period of 2010 to 2012. Their main aim was to examine the influence of PS innovative activities on business performance. Even though the obtained information was useful, it offered only a snapshot view. Therefore, the latest European Public Sector Innovation Scoreboard (EPSIS) from 2013 is a rather exploratory analysis, established on definite available data and the information from previous Innobarometer studies. The overall results indicate that the PS in Europe is innovative but it still encounters a number of challenges and internal barriers which may impact the effectiveness of the government in general.

Beside the already mentioned studies, a very important questionnaire was distributed by the Australian Public Sector Innovation Indicators Project (APSII) which used the conceptual model in order to measure PSI in Australia. According to Australian Public Service Commission (APSC) (2012) the survey asked for five main types of innovation, the process innovations, investments in innovation, communication and policy innovations, product and service, and innovation strategies, and additionally asked for the examples of most and least successful innovation. Early results indicated that the respondents have difficulties in differentiating the five innovation types.

The contribution of this paper, with respect to other research, is the development of a measuring PSI performance instrument in $\mathrm{FBiH}$ which identifies several factors of each construct in accordance with prior reviewed research as of Andersen, Jakobsen (2018), Daglio, Gerson, Kitchen (2014), Kurz, Hüsig, Dowling (2018), Mongey (2013), Taylor (2018), and others. Finally, this research will deepen the understanding on measuring public sector innovation performance in the current literature. 


\section{Research methodology Data}

The instrument of measuring PSI performance was based on four latent constructs, namely, innovation capabilities, wider sector conditions for innovation, sources of information and the share of creative occupation. The first two constructs were adopted from Hughes, Moore, Kataria (2011) as part of an existing framework for measuring PSI in the United Kingdom. The innovation capability relates to the focal underpinning institutional capabilities which can sustainably impact innovation within an institution. Furthermore, wider sector conditions for innovation relate to factors which may either support or hinder innovation. The construct for sources of information was adopted from the APSC (2012), where this term refers to drawing on a wide range of information sources by which innovation can be successfully developed and implemented. Finally, the fourth construct was chosen following Hollanders, Arundel, Buligescu (2013). The share of creative occupation refers to an enabler from the point of human resources dimension and factors which contribute to their creativity that later impacts innovative behaviour. This "creative class" is said to foster an open, dynamic and professional environment.

The primary data was obtained through a survey with close-ended questions which was completed by the employees of the PS institutions in the Federation of Bosnia and Herzegovina (FBiH). The population for the analysis consisted of all PS institutions in $\mathrm{FBiH}$, including 16 ministries, 2 agencies, and 11 institutes.

Fricker (2008) underlines that surveys which facilitate a mailing list-based sampling structure can be regarded in the same way as the traditional survey structures. Accordingly, random sampling is used in this research and solely the e-mail address from each unit in the sample is necessary. Furthermore, Fricker (2008) explains that such an approach is usually used for broad homogeneous groups which have publically available e-mail addresses, as the case of PS institutions. The focal criteria for the population in the paper is that the person is a PS employee in the $\mathrm{FBiH}$. The minimal size of the sample was set at 200 participants, which is according to Hair et al. (2010) enough for a multivariate analysis.

In order to perform the research a five-level Likert scale was used in a range from 1 (absolutely do not agree) to 5 (absolutely agree), as well as in the range from 1 (absolutely hinder) to 5 (absolutely support). The survey questions were adopted from previously recognised articles (i.e. Fernandez, Moldogaziev, 2012, Lewis, Ricard, Klijn, 2018, Singh, Sarkar, 2019), and additionally, from existing measurement items found in the literature on measuring innovation (i.e. APSC, 2012, Hollanders, Arundel, Buligescu, 2013, Hughes, Moore, Kataria, 2011).

A sample survey was piloted on 30 e-mail addresses from the public sector in the $\mathrm{FBiH}$ five days before it was officially sent to all PS employees in $\mathrm{FBiH}$. The validity and the comprehension of the questions was tested. The survey was sent in a form of a link over the email so that a direct feedback could be obtained. Based on the collected comments, a few corrections were made and some questions were accordingly rephrased.

Consequently, the final questionnaire was developed. It comprised of 25 items for measuring innovation capabilities, 12 items for wider public sector conditions for innovation, 10 items for measuring information sources, and 19 items for the share of creative occupation. The survey was sent on the 17th of July 2019, through the Lime Survey Software and it was open until the $3^{\text {rd }}$ August 2019. During that period, 291 PS employees completed and submitted the questionnaire. 


\section{Methods}

The exploratory factor analysis (EFA) was used in order to determine the principal components of measuring public sector innovation performance. Prior to that, some data from this research was missing as several employees have not submitted a response to certain questions, and this is not negligible. In that regard, a missing value analysis (MVA) was performed. There were in total 291 survey responses, and following Hair et al. (2010), all observations from the sample with more than $15 \%$ of missing data were excluded. After this step, 214 responses remained for the analysis, which represented an adequate sample size. When it comes to the analysis of data randomness, a Little MCAR test was used, in order to show if there is a significant difference between the observed sample of missing data and the sample of randomness. The test results (Chi-Square $=7118.787, \mathrm{df}=7082, \mathrm{Sig} .=.377$ ) showed a significant difference between the missing data, the sample, and the randomness sample. According to Hair et al. (2010), the missing data in the research is missing entirely at random which means that the variables are unrelated to other measured variables. Moreover, as the data was missing entirely at random, the missing values were inserted through regression imputation. Furthermore, in analysing the collected data, Hair et al. (2010) mention that extremely high or extremely low values in the sample, or the outliers, have to be identified. With the aim to identify any multivariate outliers, the Mahalanobis ( $\left.D^{2}\right)$ method was used. Mahalanobis $D^{2}$ measures the distance of each observation of a multidimensional space relative to the centre of the mean values of all observations by calculating the value of each observation regardless of the number of variables. Thus, the measure $D^{2}$ is divided by the number of variables included - $\mathrm{D}^{2} / \mathrm{df}$, in order to identify outliers in the observed significance level of 0.005 or 0.001 . The result of $0.0000056-1.0000000$ was obtained, whereas the threshold, according to Hair et al. (2010), is 3.5. Therefore, it was concluded that there are no outliers and that also all observations can be used in the further analysis.

As already mentioned, the measurement scale validity was evaluated by using the exploratory factor analysis. Through this approach it was possible to condense a larger number of items into a smaller set, as suggested by Hair et al. (2010). The EFA was used to determine the appropriate number of latent factor structures and to analyse the number of fundamental factors in the set of items in each construct (Ramli, AbuHassan, Arifin, 2017). Furthermore, the purpose of EFA was to examine and identify the underlying factor structure for the observed variables, but without setting a preconceived structure on the outcome. Moreover, the results offered a clear estimation of the factor structure of variables.

According to Kline (2013), the exploratory factor analysis is effective in less mature areas of research, in which the underlying measurement questions are still not resolved. By using the SPSS 22, EFA was conducted in the way that initial extraction was performed, the number of factors to retain was determined, the rotation or transformation was done and finally the solution was interpreted and the factor scores were calculated. The EFA employed the principal component analysis (PCA) as the extraction method, and the Varimax rotation as a factor rotation method.

\section{Results and Discussion}

According to Lattin, Carroll, Green (2003), the two main assumptions of a factor analysis, the multivariate normality and sampling adequacy, should be satisfied prior to extracting the factors in order to confirm the data suitability for the EFA. The Bartlett's test of sphericity determines the variables multivariate normality and is used to validate the hypothesis that a correlation matrix is an identity matrix. George, 
Mallery (2016) emphasise that the aim of the KMO test is to assess the sampling adequacy or whether the values distribution is appropriate for the factor analysis.

Following Hair et al. (2010), the criteria in determining the number of factors and items was based on the three main principles. Firstly, the value of the Kaiser-MeyerOlkin (KMO) test had to be above 0.60. Secondly, in order to verify whether the correlation between the variables is large enough for the factor analysis, the factor significant value of the Bartlett's test had to be below 0.001 .

When it comes to the data analysis, firstly the adequacy of the data was tested by using the mentioned KMO and Bartlett's Test. The results in Table 1 show that the KMO measure of sampling adequacy for all four constructs is in the range between 0.840 and 0.918, meaning that the values are near 1.0 and significantly above the recommended threshold value. Moreover, the Bartlett's Test, with value of p equal to 0.000 , is significant for all four constructs. Both results indicate that the data is adequate for conducting the factor analysis.

The overall results of the factor analysis for all four constructs are also presented in Table 1. The PCA for innovation capabilities extracted four component dimensions with eigenvalues more than 1.0, and these four components are able to explain $66.43 \%$ of the construct. In terms of the second construct, the PCA extracted two components with eigenvalues above 1.0, and stated that the cumulative capability of these components is able to explain $55.52 \%$ of the wider public sector conditions for innovation construct. The PCA of analysing the sources of information construct extracted two components with eigenvalues more than 1.0, explaining $65.88 \%$ of the construct. In terms of the share of creative occupation construct, the analysis extracted five component dimensions with initial eigenvalues exceeding 1.0 which are able to explain $77.53 \%$ of the construct.

Table 1 Data Adequacy and Factor Analysis results

\begin{tabular}{|l|r|r|r|r|}
\hline \multicolumn{1}{|c|}{ Construct } & $\begin{array}{c}\text { KMO } \\
\text { Test } \\
\text { Result }\end{array}$ & $\begin{array}{c}\text { Bartlett's Test } \\
\text { Significant } \\
\text { Value Result }\end{array}$ & $\begin{array}{c}\text { Number of } \\
\text { Components } \\
\text { with Initial } \\
\text { Eigenvalues } \\
\text { more than } \\
1.00\end{array}$ & $\begin{array}{r}\text { Cumulative } \\
\text { Rotation } \\
\text { Sums of } \\
\text { Squared } \\
\text { Loading }\end{array}$ \\
\hline Innovation Capabilities & 0.918 & 0.000 & 4 & $66.43 \%$ \\
\hline $\begin{array}{l}\text { Wider Public Sector Conditions } \\
\text { for Innovation }\end{array}$ & 0.879 & 0.000 & 2 & $55.52 \%$ \\
\hline Sources of Information & 0.840 & 0.000 & 2 & $65.88 \%$ \\
\hline Share of Creative Occupation & 0.888 & 0.000 & 5 & $77.53 \%$ \\
\hline
\end{tabular}

Source: Author's work.

With the EFA, two key steps were conducted, the factor extraction and the factor rotation which enhances the explanation of a factor solution as Pallant (2013) underlines. Principal component analysis was used as extraction method of the data as its main aim is to reduce and summarise the data, and define the factors, as recommended by Hair et al. (2010). The Varimax rotation was conducted in order to maximise the factor loadings variance and reduce the number of variables with high loadings over each other, following Pallant (2013). Finally, in order for an item to be included in every construct, the factor loading for each item had to be larger than 0.60 .

The innovation capabilities construct was measured by using a five-level Likert scale which ranged from 1 (absolutely do not agree) to 5 (absolutely agree). The rotation 
converged in six iterations and the results of the reliability analysis for this construct are outlined in Table 2.

Table 2 Rotated Component Matrix for Innovation Capabilities

\begin{tabular}{|c|c|c|c|c|c|}
\hline \multirow{3}{*}{ No. } & \multicolumn{5}{|l|}{ Rotted Component Matrix } \\
\hline & & \multicolumn{4}{|c|}{ Component } \\
\hline & & 1 & 2 & 3 & 4 \\
\hline 1 & $\begin{array}{l}\text { I have enough resources (equipment and supplies) to } \\
\text { do my job }\end{array}$ & & & & \\
\hline 2 & $\begin{array}{l}\text { I have the freedom to look for new technologies, } \\
\text { processes, techniques and / or ideas in the workplace }\end{array}$ & & 0.592 & & \\
\hline 3 & $\begin{array}{l}\text { The expectations of the employees in the institution are } \\
\text { well-communicated (we know what is expected of us } \\
\text { in the workplace) }\end{array}$ & & 0.603 & & \\
\hline 4 & $\begin{array}{l}\text { The current state of the institution is well communicated } \\
\text { by the manager }\end{array}$ & & & & \\
\hline 5 & $\begin{array}{l}\text { Employees at my institution are encouraged to } \\
\text { develop new ideas }\end{array}$ & & 0.772 & & \\
\hline 6 & $\begin{array}{l}\text { Employees receive fair and constructive feedback on } \\
\text { their new ideas }\end{array}$ & & 0.793 & & \\
\hline 7 & My manager shows confidence in my work & 0.747 & & & \\
\hline 8 & My manager sets goals appropriately & 0.808 & & & \\
\hline 9 & $\begin{array}{l}\text { My manager encourages me to take risks, and it is } \\
\text { perfectly fine to go wrong in trying }\end{array}$ & 0.741 & & & \\
\hline 10 & My manager encourages subordinates to do their best & 0.844 & & & \\
\hline 11 & My manager talks optimistically about the future & 0.742 & & & \\
\hline 12 & $\begin{array}{l}\text { My manager cites others to look at problems from } \\
\text { many different angles }\end{array}$ & 0.817 & & & \\
\hline 13 & My manager values employee contributions & 0.741 & & & \\
\hline 14 & $\begin{array}{l}\text { My supervisor encourages subordinates to rethink their } \\
\text { ideas }\end{array}$ & 0.827 & & & \\
\hline 15 & Promotions in my work unit are based on merit & & 0.821 & & \\
\hline 16 & $\begin{array}{l}\text { Employees are rewarded for providing high quality } \\
\text { services }\end{array}$ & & 0.854 & & \\
\hline 17 & $\begin{array}{l}\text { At my institution, people are rewarded for new ideas } \\
\text { that work well }\end{array}$ & & 0.830 & & \\
\hline 18 & My efforts have been rewarded the way it should be & & 0.729 & & \\
\hline 19 & $\begin{array}{l}\text { In the workplace, I am constantly looking for new } \\
\text { processes, techniques and / or new ideas for doing } \\
\text { work activities }\end{array}$ & & & 0.751 & \\
\hline 20 & $\begin{array}{l}\text { In the workplace, I promote and spread ideas to other } \\
\text { colleagues }\end{array}$ & & & 0.757 & \\
\hline 21 & I share the information I gained with my colleagues. & & & 0.720 & \\
\hline 22 & $\begin{array}{l}\text { I find it important that my colleagues know what I'm } \\
\text { working on. }\end{array}$ & & & 0.747 & \\
\hline 23 & $\begin{array}{l}\text { I often communicate with a representative of a } \\
\text { business association }\end{array}$ & & & & 0.865 \\
\hline 24 & $\begin{array}{l}\text { I often communicate with a leader of a medium or } \\
\text { large private company }\end{array}$ & & & & 0.832 \\
\hline 25 & $\begin{array}{l}\text { I often communicate with an officer at another federal } \\
\text { institution }\end{array}$ & & & & 0.618 \\
\hline
\end{tabular}

Source: Author's work. 
The Table 2 showed the factor loadings of the innovation capabilities construct consisting of 25 items over four components, from number 1 to 4 . In Table 3, on the next page, the final results of the construct can be seen, where items 7-14 belong to component 1, items 2, 3, 5, 6, 15-18 belong to component 2, items 19-22 belong to component 3, and items 23,24 and 25 belong to component 4. Because of low factor loadings, two items were removed from the original 25 items.

According to Awang et al. (2015) a component with Cronbach's alpha of 0.6 or higher, indicates that the items of a particular component present a reliable internal consistency measure. The values of the Cronbach alpha for the sub-constructs 1 to 4 are $0.930,0.947,0.756$ and 0.694 , respectively, and the value for the consolidated four components is 0.925 . It can be seen that the focal underpinning institutional capabilities which can sustainably impact innovation within an institution are in accordance with prior research made by Head (2013), Taylor (2018), Kurz, Hüsig, Dowling (2018), and Mongey (2013). In the case of FBiH these components are leadership, people management, proactiveness and networking.

Table 3 Final Items of Innovation Capabilities

\begin{tabular}{|c|c|}
\hline Items & $\begin{array}{c}\text { Cronbach } \\
\text { Alpha for the } \\
\text { Sub-Construct }\end{array}$ \\
\hline Component 1: Leadership & \multirow{9}{*}{0.930} \\
\hline My manager shows confidence in my work & \\
\hline My manager sets goals appropriately & \\
\hline $\begin{array}{l}\text { My manager encourages me to take risks, and it is perfectly fine to go } \\
\text { wrong in trying }\end{array}$ & \\
\hline My manager encourages subordinates to do their best & \\
\hline My manager talks optimistically about the future & \\
\hline My manager cites others to look at problems from many different angles & \\
\hline My manager values employee contributions & \\
\hline My supervisor encourages subordinates to rethink their ideas & \\
\hline Component 2: People Management & \multirow[t]{9}{*}{0.947} \\
\hline $\begin{array}{l}\text { I have the freedom to look for new technologies, processes, techniques } \\
\text { and/ or ideas in the workplace }\end{array}$ & \\
\hline $\begin{array}{l}\text { The expectations of the employees in the institution are well- } \\
\text { communicated (we know what is expected of us in the workplace) }\end{array}$ & \\
\hline Employees at my institution are encouraged to develop new ideas & \\
\hline Employees receive fair and constructive feedback on their new ideas & \\
\hline Promotions in my work unit are based on merit & \\
\hline Employees are rewarded for providing high quality services & \\
\hline At my institution, people are rewarded for new ideas that work well & \\
\hline My efforts have been rewarded the way it should be & \\
\hline Component 3: Proactiveness & \multirow[t]{5}{*}{0.756} \\
\hline $\begin{array}{l}\text { In the workplace, I am constantly looking for new processes, techniques } \\
\text { and / or new ideas for doing work activities }\end{array}$ & \\
\hline In the workplace, I promote and spread ideas to other colleagues & \\
\hline I share the information I gained with my colleagues. & \\
\hline I find it important that my colleagues know what I'm working on. & \\
\hline Component 4: Networking & \multirow[t]{4}{*}{0.694} \\
\hline I often communicate with a representative of a business association & \\
\hline I often communicate with a leader of a medium or large private company & \\
\hline I often communicate with an officer at another federal institution & \\
\hline Cronbach Alpha for the Construct & 0.925 \\
\hline
\end{tabular}

Source: Author's work. 
The descriptive statistics for the Innovation Capabilities construct are presented in Table 4. The variables were computed as means so that they have the same scale (from 1 to 5) as the input variables. Accordingly, it may be concluded that "Proactiveness" is rated the best, while "People Management" is rated worst.

Table 4 Descriptive statistics for Innovation Capabilities

\begin{tabular}{|l|r|r|r|r|r|}
\hline & $\mathrm{N}$ & Min & Max & Mean & $\begin{array}{c}\text { Std. } \\
\text { deviation }\end{array}$ \\
\hline Component 1: Leadership & 214 & 1 & 5 & 3.78 & 1.03 \\
\hline Component 2: People Management & 214 & 1 & 5 & 2.73 & 1.10 \\
\hline Component 3: Proactiveness & 214 & 1.75 & 5 & 3.91 & 0.67 \\
\hline Component 4: Networking & 214 & 1 & 5 & 2.81 & 1.21 \\
\hline
\end{tabular}

Source: Author's work.

The wider public sector conditions for innovation construct was measured by using a five-level Likert scale which ranged from 1 (absolutely hinder) to 5 (absolutely support). The rotation converged in three iterations and the results of the reliability analysis for this construct are outlined in Table 5.

Table 5 Rotated Component Matrix for Wider Sector Conditions

\begin{tabular}{|c|c|c|c|}
\hline \multirow{3}{*}{ No. } & \multicolumn{3}{|l|}{ Rotated Component Matrix } \\
\hline & & Comp & nent \\
\hline & & 1 & 2 \\
\hline 1 & Annual budget & & \\
\hline 2 & Salary and promotion system & 0.766 & \\
\hline 3 & Values and culture of the executive management & 0.729 & \\
\hline 4 & Institutional structure & 0.759 & \\
\hline 5 & Quality of ideas coming from the employees & & \\
\hline 6 & Values and culture of the politicians & 0.778 & \\
\hline 7 & Quality of the policy proposals & 0.761 & \\
\hline 8 & National government pressure on the $\mathrm{FBiH}$ & 0.666 & \\
\hline 9 & EU directives & & 0.666 \\
\hline 10 & Economic crisis & 0.654 & \\
\hline 11 & Media attention & & 0.703 \\
\hline 12 & Citizen involvement & & 0.771 \\
\hline
\end{tabular}

Source: Author's work.

The factor loadings of 12 items of this construct fall under two main components. In Table 6 it can be seen that items 2-4, 6-8 and 10 belong to component 1, and items 9 , 11 and 12 belong to component 2. Due to low factor loadings, items 1 and 5 were dropped. The Cronbach alpha value for component 1 is 0.891 and 0.608 for component 2, while the consolidated value also exceeds the minimum and equals 0.878. Furthermore, in Table 6, it can be noticed that the factors which may either support or hinder innovation can be internal and external which was also supported by Mongey (2013), Bland et al. (2010), and Andersen, Jakobsen (2018).

The descriptive statistics for the Wider Sector Conditions construct are presented in Table 7. Accordingly, it may be concluded that "External" is rated the best, while "Internal" is rated worst.

The construct for sources of information was measured by using a five-level Likert scale which ranged from 1 (absolutely do not agree) to 5 (absolutely agree). The rotation converged in three iterations and the results of the reliability analysis for this construct are outlined in Table 8. 
Table 6 Final Items for Wider Sector Conditions

\begin{tabular}{|c|c|}
\hline Items & $\begin{array}{c}\text { Cronbach Alpha } \\
\text { for the Sub-Construct }\end{array}$ \\
\hline Component 1: Internal & \multirow[t]{8}{*}{0.891} \\
\hline Salary and promotion system & \\
\hline Values and culture of the executive management & \\
\hline Institutional structure & \\
\hline Values and culture of the politicians & \\
\hline Quality of the policy proposals & \\
\hline National government pressure on the $\mathrm{FBiH}$ & \\
\hline Economic crisis & \\
\hline Component 2: External & \multirow[t]{4}{*}{0.608} \\
\hline EU directives & \\
\hline Media attention & \\
\hline Citizen involvement & \\
\hline Cronbach Alpha for the Construct & 0.878 \\
\hline
\end{tabular}

Source: Author's work.

Table 7 Descriptive statistics for Wider Sector Conditions

\begin{tabular}{|l|c|r|r|r|r|}
\hline & $\mathrm{N}$ & Min & Max & Mean & \multicolumn{1}{c|}{ Std. deviation } \\
\hline Component 1: Internal & 214 & 1 & 5 & 2.81 & 1.09 \\
\hline Component 2: External & 214 & 1 & 5 & 3.29 & 0.83 \\
\hline
\end{tabular}

Source: Author's work.

Table 8 Rotated Component Matrix for Sources of Information

\begin{tabular}{|c|l|c|c|}
\hline \multirow{2}{*}{ No. } & \multicolumn{1}{|c|}{ Rotated Component Matrix } & \multicolumn{2}{c|}{ Component } \\
\cline { 3 - 4 } & & 1 & 2 \\
\hline 1 & I have enough information about my institution's current activities & & 0.741 \\
\hline 2 & In due time, I receive relevant work information from my supervisor & & 0.902 \\
\hline 3 & I get complete and accurate information all the time & & 0.872 \\
\hline 4 & $\begin{array}{l}\text { The frequency of communication between the supervisor and } \\
\text { myself is excellent, i.e. I get regular job instructions }\end{array}$ & & 0.849 \\
\hline 5 & I like to be fully informed of what my colleagues know & 0.642 & \\
\hline 6 & When I need some knowledge, I ask my colleagues about it & 0.801 & \\
\hline 7 & I regularly inform my colleagues about what I am working on & 0.771 & \\
\hline 8 & $\begin{array}{l}\text { When I have learned something new, I have made sure my } \\
\text { colleagues learned about it }\end{array}$ & 0.811 & \\
\hline 9 & I ask my colleagues about their skills when I want to learn something & 0.811 & \\
\hline 10 & When a colleague is good at something, I ask him to teach me & 0.803 & \\
\hline
\end{tabular}

Source: Author's work.

The factor loadings of ten items of this construct fall under two main components. In Table 9 it can be seen that items 1-4 belong to component 1, and items 5-10 belong to component 2. No items were dropped for sources of information. The Cronbach alpha value for component 1 is 0.869 and 0.866 for component 2, while the consolidated value equals 0.832. Moreover, it can be noticed that the two components of sources of information, following Daglio, Gerson, Kitchen (2014), Abukhait, Bani-Melhem, Zeffane (2019), may be named as receiving information and searching for it.

The descriptive statistics for the Sources of Information construct are presented in Table 10. Accordingly, it may be concluded that "Searching Information" is rated the best, while "Receiving Information" is rated worst. 
Table 9 Final Items for Sources of Information

\begin{tabular}{|c|c|}
\hline Items & $\begin{array}{l}\text { Cronbach } \\
\text { Alpha for the } \\
\text { Sub-Construct }\end{array}$ \\
\hline Component 1: Receiving Information & \multirow{5}{*}{0.869} \\
\hline I have enough information about my institution's current activities & \\
\hline In due time, I receive relevant work information from my supervisor & \\
\hline I get complete and accurate information all the time & \\
\hline $\begin{array}{l}\text { The frequency of communication between the supervisor and myself is } \\
\text { excellent, i.e. I get regular job instructions }\end{array}$ & \\
\hline Component 2: Searching Information & \multirow[t]{7}{*}{0.866} \\
\hline I like to be fully informed of what my colleagues know & \\
\hline When I need some knowledge, I ask my colleagues about it & \\
\hline I regularly inform my colleagues about what I am working on & \\
\hline $\begin{array}{l}\text { When I have learned something new, I have made sure my colleagues } \\
\text { learned about it }\end{array}$ & \\
\hline I ask my colleagues about their skills when I want to learn something & \\
\hline When a colleague is good at something, I ask him to teach me & \\
\hline Cronbach Alpha for the Construct & 0.832 \\
\hline
\end{tabular}

Source: Author's work.

Table 10 Descriptive statistics for Sources of Information

\begin{tabular}{|l|r|r|r|r|r|}
\hline & $\mathrm{N}$ & Min & Max & Mean & Std. deviation \\
\hline Component 1: Receiving Information & 214 & 1 & 5 & 3.37 & 0.74 \\
\hline Component 2: Searching Information & 214 & 1 & 5 & 4.02 & 0.72 \\
\hline
\end{tabular}
Source: Author's work.

The construct for the share of creative occupation was measured by using a fivelevel Likert scale which ranged from 1 (absolutely do not agree) to 5 (absolutely agree). The rotation converged in six iterations and the results of the reliability analysis for this construct are outlined in Table 11.

The factor loadings of 19 items for share of creative occupation fall under five main components. In Table 12 it can be seen that items 7, 12-14 belong to component 1 , items 8-11 belong to component 2, items 16-19 belong to component 3, items 4, 5 and 6 belong to component 4 and item 2 and 3 belong to component 5. Due to low factor loading, items 1 and 15 were removed. The values of the Cronbach alpha for the subconstructs 1 to 5 are $0.929,0.929,0.848,0.873$ and 0.864 , respectively, and the value for the consolidated five components is 0.910 . It may be noticed that the final components of share of creative occupation, which follow the research if Mongey (2013), and Rivera-León, Simmonds, Roman (2012), are appreciation, inspiration, personal proactiveness, trust and independence, and competencies.

The descriptive statistics for the Share of Creative Occupation construct are presented in Table 13. Accordingly, it may be concluded that "Competencies" is rated the best, while "Appreciation" is rated worst. 
Table 11 Rotated Component Matrix for Share of Creative Occupation

\begin{tabular}{|c|c|c|c|c|c|c|}
\hline \multirow{3}{*}{ No. } & \multicolumn{6}{|c|}{ Rotated Component Matrix } \\
\hline & & \multicolumn{5}{|c|}{ Component } \\
\hline & & 1 & 2 & 3 & 4 & 5 \\
\hline 1 & The job I do is very important to me & & & & & \\
\hline 2 & I feel competent to perform the tasks & & & & & 0.914 \\
\hline 3 & $\begin{array}{l}\text { I am confident in my own abilities and skills necessary to perform } \\
\text { the assigned tasks }\end{array}$ & & & & & 0.866 \\
\hline 4 & $\begin{array}{l}\text { I have the authority to make the necessary decisions to do my job } \\
\text { well }\end{array}$ & & & & 0.803 & \\
\hline 5 & $\begin{array}{l}\text { My supervisor trusts me and allows me to make the right decisions } \\
\text { at work }\end{array}$ & & & & 0.763 & \\
\hline 6 & $\begin{array}{l}\text { I have opportunities for independence and freedom in how I do } \\
\text { my job }\end{array}$ & & & & 0.791 & \\
\hline 7 & Creative work is appreciated and recognized in my institution & 0.763 & & & & \\
\hline 8 & My manager or supervisor serves as a good role model & & 0.815 & & & \\
\hline 9 & I can talk freely and openly with my manager & & 0.799 & & & \\
\hline 10 & My manager builds the identity and morale of the team & & 0.819 & & & \\
\hline 11 & My manager inspires confidence with his arguments & & 0.798 & & & \\
\hline 12 & $\begin{array}{l}\text { Advancement in a position depends on how well the employees } \\
\text { do their job }\end{array}$ & 0.872 & & & & \\
\hline 13 & $\begin{array}{l}\text { The rewards in my work unit depend on how well the employees } \\
\text { do their job }\end{array}$ & 0.900 & & & & \\
\hline 14 & Creativity and innovation are rewarded & 0.889 & & & & \\
\hline 15 & I get timely praise for my ideas/ work & & & & & \\
\hline 16 & I have creative ideas at work all the time & & & 0.799 & & \\
\hline 17 & In the workplace, I try to implement new ideas & & & 0.850 & & \\
\hline 18 & $\begin{array}{l}\text { In the workplace, I develop adequate plans and schedules to } \\
\text { implement new ideas }\end{array}$ & & & 0.852 & & \\
\hline 19 & $\begin{array}{l}\text { In the workplace, I am able to try new ways to solve the problems } \\
\text { I encounter while working }\end{array}$ & & & 0.670 & & \\
\hline
\end{tabular}

Source: Author's work.

\section{Table 12 Final Items for Share of Creative Occupation}

\begin{tabular}{|l|r|}
\hline \multicolumn{1}{|c|}{ Items } & $\begin{array}{r}\text { Cronbach } \\
\text { Alpha for the } \\
\text { Sub-Construct }\end{array}$ \\
\hline Component 1: Appreciation & 0.929 \\
\hline Creative work is appreciated and recognized in my institution & \\
\hline Advancement in a position depends on how well the employees do their job & \\
\hline The rewards in my work unit depend on how well the employees do their job & \\
\hline Creativity and innovation are rewarded & \\
\hline Component 2: Inspiration & \\
\hline My manager or supervisor serves as a good role model & \\
\hline I can talk freely and openly with my manager & \\
\hline My manager builds the identity and morale of the team & \\
\hline My manager inspires confidence with his arguments & \\
\hline Component 3: Personal proactiveness & \\
\hline I have creative ideas at work all the time & \\
\hline In the workplace, I try to implement new ideas & \\
\hline In the workplace, I develop adequate plans and schedules to implement new ideas \\
\hline $\begin{array}{l}\text { In the workplace, I am able to try new ways to solve the problems I encounter while } \\
\text { working }\end{array}$ \\
\hline Component 4: Trust \& independence \\
\hline I have the authority to make the necessary decisions to do my job well \\
\hline My supervisor trusts me and allows me to make the right decisions at work \\
\hline I have opportunities for independence and freedom in how I do my job \\
\hline Component 5: Competencies \\
\hline I feel competent to perform the tasks \\
\hline I am confident in my own abilities and skills necessary to perform the assigned tasks \\
\hline Cronbach Alpha for the Construct \\
\hline Soure: Author's work. \\
\hline
\end{tabular}

Source: Author's work. 
Table 13 Descriptive statistics for Share of Creative Occupation

\begin{tabular}{|l|c|r|r|r|r|}
\hline & $\mathrm{N}$ & Min & Max & Mean & Std. deviation \\
\hline Component 1: Appreciation & 214 & 1 & 5 & 2.50 & 1.15 \\
\hline Component 2: Inspiration & 214 & 1 & 5 & 3.41 & 1.08 \\
\hline Component 3: Personal proactiveness & 214 & 1 & 5 & 3.79 & 0.76 \\
\hline Component 4: Trust \& independence & 214 & 1 & 5 & 3.68 & 1.03 \\
\hline Component 5: Competencies & 214 & 1 & 5 & 4.53 & 0.63 \\
\hline
\end{tabular}

Source: Author's work.

\section{Conclusion}

The main aim of this paper was to provide some empirical support regarding the reliability of the instrument which was developed in order to measure PSI, by using exploratory factor analysis. This research empirically supported some previous research results regarding the main constructs in measuring innovation performance in the PS. Various notable initiatives have happened in Europe and outside with the aim to enhance the understanding of public sector innovation and to examine the data collection tools, but rather narrow data was collected, so that additional research is advisable.

The results indicate that the questionnaire used to measure innovation capabilities, wider sector conditions for innovation, sources of information and the share of creative occupation construct is reliable. The factor analysis produced four factors for innovation capabilities, two for wider public sector conditions for innovation, two for sources of information and five factors for share of creative occupation. Each component was able to explain from $65 \%$ to $78 \%$ of the construct. The reliability analysis results showed that items from all four constructs are relevant for this research setting and contribute to the general reliability instrument with a high Cronbach's alpha value, ranging from 0.832 to 0.932 .

The main analysis results showed that innovation capabilities were measured by using four sub-constructs, which are leadership, people management, proactiveness and networking. Prior research by Head (2013) and Taylor (2018) also confirmed that factors that can influence the innovation performance in the PS, among others, encompass superior leadership and project management skills, networking. Furthermore, Mongey (2013) explained the management is the one who supports innovation, improves people management, and the establishes a common entrepreneurial objective within the institution.

The wider public sector conditions construct was measured through two subconstructs that are internal and external. Mongey (2013) also explained that every successful institution requires an overall understanding of the internal conditions affecting innovation. Bland et al. (2010) emphasised that resources, talent and quality skills are necessary in order to place innovative ideas into practice. The support of the whole institutional structure is a key for a successful implementation of the innovative institutional activities. Furthermore, Andersen, Jakobsen (2018) verified that in order to understand the public sector performance, it is also important to consider the external factors, as the political pressure, horizontal factors as compliance pressures, citizen needs and others.

The sources of information construct were measured using two sub-constructs, which are receiving and searching information. Daglio, Gerson, Kitchen (2014) verified that searching and sharing information is essential for the improvement of innovation. Furthermore, Abukhait, Bani-Melhem, Zeffane (2019) also explained that knowledge sharing includes a mutual exchange of task information and working expertise in which it enhances innovative employee behaviour and fosters critical thinking. 
The share of creative occupation was measured through five sub-constructs that are appreciation, inspiration, personal proactiveness, trust and independence, and competencies. Mongey (2013) also underlined that PS institutions should inspire, encourage and appreciate their employees in innovating. Inspiration is, in most cases, intrinsic, but it is also highly dependent on the working environment, whereas opportunity refers mostly on the provision of trust and independence, and resources. Rivera-León, Simmonds, Roman (2012) explained that it is probable that innovation will occur in institutional cultures, which stimulate and provide rewards based on competencies and personal endeavour.

These results facilitated the identification of suitable factors and number of factors reflecting innovation capabilities, wider sector conditions for innovation, sources of information and the share of creative occupation in the $\mathrm{FBiH}$ public sector. Even though the Cronbach's alpha value of each construct exceeded the minimum threshold which was set by Awang et al. (2015), the conduction of a more rigorous analysis may be recommended in order confirm the validity and reliability, for example by using the confirmatory factor analysis.

Nevertheless, this research is a good starting point as it has provided and analysed the first instrument in measuring public sector innovation performance in $\mathrm{FBiH}$. Furthermore, as the area of public sector innovation in $\mathrm{FBiH}$ is still vague this instrument can be used to assess the current situation and decide on some further steps in order to enhance PSI in the entity and the country.

The main contribution of this paper was the development of the first measuring instrument of PSI performance in the context of Federation of Bosnia and Herzegovina. This research provided an empirical support on the reliability and the identification of several factors of each construct and deepened the understanding on measuring public sector innovation performance in the current literature and in a developing country context.

\section{References}

1. Abukhait, R. M., Bani-Melhem, S., Zeffane, R. (2019). Empowerment, Knowledge Sharing and Innovative Behaviours: Exploring Gender Differences. International Journal of Innovation Management, Vol. 23, No. 1, pp. 1-28.

2. Albury, D. (2005). Fostering innovation in public services. Public money and management, Vol. 25, No. 1, pp. 51-56.

3. Andersen, S. C., Jakobsen, M. L. (2018). Political Pressure, Conformity Pressure, and Performance Information as Drivers of Public Sector Innovation Adoption. International Public Management Journal, Vol. 21, No. 2, pp. 213-242.

4. Armbruster, H., Bikfalvi, A., Kinkel, S., Lay, G. (2008). Organizational innovation: The challenge of measuring non-technical innovation in large-scale surveys. Technovation, Vol. 28, No. 10 , pp. 644-657.

5. Audenaert, M., Decramer, A., George, B., Verschuere, B., Van Waeyenberg, T. (2019). When employee performance management affects individual innovation in public organizations: The role of consistency and LMX. The International Journal of Human Resource Management, Vol. 30, No. 5, pp. 815-834.

6. Australian Public Service Commission (APSC) (2012). State of the Service Report: State of the Service Series 2010-2011. Canberr, Commonwealth of Australia.

7. Awang, Z., Afthanorhan, A., Mohamad, M., Asri, M. A. M. (2015). An evaluation of measurement model for medical tourism research: the confirmatory factor analysis approach. International Journal of Tourism Policy, Vol. 6, No. 1, pp. 29-45.

8. Bailey, S. J. (2002). Public sector economics: theory, policy and practice. Basingstroke, Palgrave Macmillan.

9. Bartlett, D., Dibben, P. (2002). Public sector innovation and entrepreneurship: Case studies from local government. Local government studies, Vol. 28, No. 4, pp. 107-121. 
10.Bland, T., Bruk, B., Kim, D., Lee, K. T. (2010). Enhancing public sector innovation: Examining the network-innovation relationship. The innovation journal: The public sector innovation journal, Vol. 15, No. 3, pp. 1-17.

11.Bloch, C., Bugge, M. M. (2013). Public sector innovation - From theory to measurement. Structural change and economic dynamics, Vol. 27, No. 1, pp. 133-145.

12.Bommert, B. (2010). Collaborative innovation in the public sector. International public management review, Vol. 11, No. 1, pp. 15-33.

13.Daglio, M., Gerson D., Kitchen, H. (2014). Building Organisational Capacity for Public Sector Innovation. Paris, OECD.

14.Damanpour, F., Schneider, M. (2006). Phases of the adoption of innovation in organizations: effects of environment, organization and top managers. British journal of Management, Vol. 17, No. 3, pp. 215-236.

15.Damanpour, F., Schneider, M. (2008). Characteristics of innovation and innovation adoption in public organizations: Assessing the role of managers. Journal of public administration research and theory, Vol. 19, No. 3, pp. 495-522.

16.Fernandez, S., Moldogaziev, T. (2012). Using employee empowerment to encourage innovative behavior in the public sector. Journal of Public Administration Research and Theory, Vol. 23, No. 1, pp. 155-187.

17.Fricker, R. D. (2008). Sampling methods for web and e-mail surveys. The SAGE handbook of online research methods, Vol. 20, No.1, pp. 195-216.

18.George, D., Mallery, P. (2016). IBM SPSS Statistics 23 Step by Step: A Simple Guide and Reference. New York, Routledge.

19. Gittelman, M. (2006). National institutions, public-private knowledge flows, and innovation performance: A comparative study of the biotechnology industry in the US and France. Research Policy, Vol. 35, No. 7, pp. 1052-1068.

20.Hair, J. F., Black, W. C., Babin, B. J., Anderson, R. E. (2010). Multivariate Data Analysis. Harlow, Pearson.

21.Head, G. (2013). Creating an Innovative Public Sector. New South Wales, Public Service Commission.

22.Hollanders, H., Arundel, A., Buligescu, B. (2013). European Public Sector Innovation Scoreboard. Belgium, European Commission.

23. Hughes, A., Moore, K., Kataria, N. (2011). Innovation in Public Sector Organisations: A pilot survey for measuring innovation across the public sector. London, NESTA.

24.Kafouros, M. I., Buckley, P. J., Sharp, J. A., Wang, C. (2008). The role of internationalization in explaining innovation performance. Technovation, Vol. 28, No.1, pp. 63-74.

25.Keping, Y. (2018). Governance and Good Governance: A New Framework for Political Analysis. Fudan Journal of the Humanities and Social Sciences, Vol. 11, No. 1, pp. 1-8.

26. Kline, R. B. (2013). Exploratory and confirmatory factor analysis: Applied quantitative analysis in the social sciences. New York, Routledge.

27.Kurz, V., Hüsig, S., Dowling, M. (2018). What drives different employee types of innovative behaviour? Development and test of an integrative model of employee driven innovation in German firms. International Journal of Entrepreneurship and Innovation Management, Vol. 22, No. 4, pp. 397-426.

28.Lattin, J. M., Carroll, J.D., Green, P.E. (2003). Analyzing multivariate data. Cole Pacific Grove, Thomson Brooks.

29.Lewis, J. M., Ricard, L. M., Klijn, E. H. (2018). How innovation drivers, networking and leadership shape public sector innovation capacity. International Review of Administrative Sciences, Vol. 84, No. 2, pp. 288-307.

30.Lin, C., Lin, P., Song, F. M., Li, C. (2011). Managerial incentives, CEO characteristics and corporate innovation in China's private sector. Journal of Comparative Economics, Vol. 39, No. 2, pp. 176-190.

31.Lundvall, B. A., Nielsen, P. (2007). Knowledge management and innovation performance. International Journal of Manpower, Vol. 28, No. 3, pp. 207-223.

32.Mongey, O. (2013). Innovation in the Irish public sector. Sligo, Institute of Technology.

33. Mulgan, G., Albury, D. (2003). Innovation in the public sector. Strategy Unit, Cabinet Office, Vol. 1, No. 1, pp. 40-55. 
34. Organization for Economic Cooperation and Development. (2017). Fostering Innovation in the Public Sector. Paris, OECD Publishing.

35.Pallant, J. (2013). SPSS survival manual: a step by step guide to data analysis using IBM SPSS. Maidenhead, UK, McGraw-Hill.

36.Ramli, R. I., Abu-Hassan, N., Arifin, A. S. (2017). Exploratory Factor Analysis of Latent Constructs Used for Measuring Public Sector Innovation Performance in Malaysia. Journal of Science, Technology and Innovation Policy, Vol. 2, No. 2, pp.14-24.

37.Ricard, L. M., Klijn, E. H., Lewis, J. M., Ysa, T. (2017). Assessing public leadership styles for innovation: A comparison of Copenhagen, Rotterdam and Barcelona. Public Management Review, Vol. 19, No. 2, pp. 134-156.

38.Rivera-León, L., Simmonds, P., Roman, L. (2012). Trends and Challenges in Public Sector Innovation in Europe. Brussels, Innovation Policy Trend Chart.

39.Schot, J., Steinmueller, W. E. (2018). Three frames for innovation policy: R\&D, systems of innovation and transformative change. Research Policy, Vol. 47, No. 9, pp. 1554-1567.

40.Singh, M., Sarkar, A. (2019). Role of psychological empowerment in the relationship between structural empowerment and innovative behaviour. Management Research Review, Vol. 42, No. 4, pp. 521-538.

41.Sørensen, E., Torfing, J. (2011). Enhancing collaborative innovation in the public sector. Administration \& Society, Vol. 43, No. 8, pp. 842-868.

42.Taylor, S. P. (2018). Innovation in the public sector: dimensions, processes, barriers and developing a fostering framework. International Journal of Research Science \& Management, Vol. 5, No. 1, pp. 28-37.

43. Tiganasu, R., Pascariu, G. C., Nijkamp, P. (2019). Performance and Innovation in the Public Sector of the European Union Countries. An Analysis Based on the Dynamics of Perceptions, 2009-2016. Transylvanian Review of Administrative Sciences, Vol. 15, No. 1, pp. 94-123.

44.Vigoda-Gadot, E., Shoham, A., Schwabsky, N., Ruvio, A. (2008). Public Sector Innovation for Europe: A Multinational Eight-Country Exploration of Citizens' perspectives. Public Administration, Vol. 86, No. 2, pp. 307-329.

\section{About the authors}

Lamija Krndzija is a PhD student at University of Sarajevo School of Economics and Business. She graduated from the School of Economics and Business, University of Sarajevo, majoring in financial management, and she gained a postgraduate master degree in public sector management at the University of Ljubljana School of Economics and Business. She was a student tutor in Quantitative Models in Finance and Statistics in Economics and Management at the School of Economics and Business in Sarajevo. She is currently employed at the Federal Institute for Development Programming as a strategic planning associate. Author can be contacted at lamija.krndzija@fzzpr.gov.ba. 